\title{
Efficacy and prognostic analysis of chemoradiotherapy in patients with thoracic esophageal squamous carcinoma with cervical lymph nodal metastasis alone
}

\author{
Peng Zhang ${ }^{1,2+}$, Mian Xi ${ }^{1,2+}$, Lei Zhao ${ }^{1,2}$, Qiao-Qiao Li ${ }^{1,2}$, Li-Ru He ${ }^{1,2}$, Shi-Liang Liu ${ }^{1,2}$, Jing-Xian Shen ${ }^{1,3}$ \\ and Meng-Zhong Liu ${ }^{1,2^{*}}$
}

\begin{abstract}
Background: The prognostic factors of thoracic esophageal squamous carcinoma with cervical lymph nodal metastasis (CLNM) have not been specifically investigated. This study was performed to analyze the efficacy and prognostic factors of chemoradiotherapy for thoracic esophageal carcinoma with CLNM alone.

Methods: From 2002 to 2011, 139 patients with inoperable esophageal cancer who underwent chemoradiotherapy at the Sun Yat-Sen University were retrospectively analyzed. Median radiation doses were 60 Gy (range: 50-68 Gy). Univariate and multivariate analyses were performed to compare overall survival (OS) and progression-free survival (PFS).

Results: The 1- and 3-year OS rates were $68.2 \%$ and 27.9\%, respectively. The 1- and 3-year PFS rates were 51.9\% and $20.1 \%$, respectively. The multivariate analysis demonstrated that response to treatment, $T$ stage, pathological grade, and laterality of cervical lymph nodal metastases were independent prognostic factors for thoracic esophageal carcinoma with CLNM.
\end{abstract}

Conclusions: Concurrent chemoradiotherapy is an important and hopeful treatment option for patients with esophageal cancer with CLNM alone. Our study has revealed that response to treatment, T stage, pathological grade and laterality of cervical lymph nodal metastases are significant prognostic factors for long-term survival.

Keywords: Chemoradiotherapy, Esophageal cancer, Prognosis, Cervical lymph nodal metastasis

\section{Background}

Esophageal cancer is an aggressive disease and has a liability of lymphatic and hematogenous dissemination. In addition, the prognosis of esophageal cancer is poor, and the 5-year survival rate of patients with distant metastasis is only $3 \%$ [1]. If distant metastasis occurs, the opportunity to operate is lost. For patients with inoperable esophageal cancer, chemoradiotherapy is the mainstay of

\footnotetext{
*Correspondence: liumengzhong@126.com

${ }^{\dagger}$ Equal contributors

${ }^{1}$ State Key Laboratory of Oncology in South China, Collaborative Innovation Center for Cancer Medicine, Cancer Center, Sun Yat-sen University,

Guangzhou 510060, People's Republic of China

'Department of Radiation Oncology, Cancer Center, Sun Yat-sen University,

Guangzhou 510060, People's Republic of China

Full list of author information is available at the end of the article
}

treatment. Although cervical lymph nodal metastases were designated as stage IV according the 6th American Joint Committee on Cancer (AJCC) staging system for esophageal carcinoma, the long-term survival data of patients with stage IV disease is varied. It has been reported that long-term survival might be achievable in patients with cervical lymph nodal metastases [2].

Well-known prognostic factors of esophageal cancer are TNM stage, tumor length (for early stage esophageal cancer) [3], concurrent chemotherapy, histopathological grading, sex, and age $[4,5]$. The efficacy and prognosis of thoracic esophageal squamous carcinoma with cervical lymph nodal metastasis (CLNM) alone, have not been specifically determined.

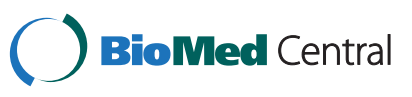

(c) 2014 Zhang et al.; licensee BioMed Central Ltd. This is an Open Access article distributed under the terms of the Creative Commons Attribution License (http://creativecommons.org/licenses/by/2.0), which permits unrestricted use, distribution, and reproduction in any medium, provided the original work is properly credited. The Creative Commons Public Domain Dedication waiver (http://creativecommons.org/publicdomain/zero/1.0/) applies to the data made available in this article, unless otherwise stated. 
Our study was performed to evaluate the efficacy and to explore the prognostic factors that are associated with overall survival (OS) and progression-free survival (PFS) in patients with thoracic esophageal squamous carcinoma with CLNM, who were treated with chemoradiotherapy.

\section{Methods \\ Patient population}

Between February 2002 and December 2011, 139 patients who were diagnosed with esophageal cancer with cervical lymph nodal metastases alone at Sun Yat-sen University Cancer Center, were retrospectively studied. Each patient had histologically confirmed squamous cell carcinoma of the esophagus, was unable to undergo radical resection, and was treated with radiotherapy plus chemotherapy. The pretreatment evaluation consisted of endoscopy, barium esophagography and a computed tomography (CT) scan of the abdomen and thorax. Endoscopic ultrasound has only been available since 2006. Bone scans were performed if clinically indicated. The 6th AJCC staging system was used in this study. The criteria for lymph node positivity on the CT scan were either (1) short axis size $>10 \mathrm{~mm}$, (2) lymph node with infiltrative margin, or (3) central necrosis. According to the 6th AJCC classification, 54 patients with upper third thoracic cancer and cervical nodal metastases were staged as IVa, and the remaining 85 patients were staged as IVb.

This study was approved by the institutional review board (IRB) of the Cancer Center, Sun Yat-sen University. Written informed consent was obtained from all the patients in accordance with the regulations of the IRB.

\section{Treatment details}

Radiotherapy was delivered with 6-10 MV photons once daily, five times a week (except weekends and public holidays), with a daily dose of 1.8-2 Gy. The total radiotherapy dose was $<60$ Gy in 45 patients and $\geq 60$ Gy in 94 patients. The majority of patients (131) received threedimensional conformal radiotherapy and the remaining eight patients received intensity-modulated radiotherapy (IMRT). The primary gross tumor volume (GTV-P) included esophageal lesions found on the radiograph and the gross tumor volume for the affected lymph nodes (GTV$\mathrm{N}$ ) was determined. The conformal primary tumor volume (CTV-P) included the GTV-P with a 3-cm margin (craniocaudal direction) and a $0.5-\mathrm{cm}$ margin (lateral and anterior-posterior directions). The CTV of the upper-third of the squamous cell carcinoma (SCC) encompassed the bilateral supraclavicular region.

Among the 139 patients, 29 received induction chemotherapy plus concurrent chemoradiotherapy. The other 110 patients received concurrent chemoradiotherapy. The induction chemotherapy was two cycles of docetaxel $\left(70 \mathrm{mg} / \mathrm{m}^{2}\right)$ and cisplatin $\left(80 \mathrm{mg} / \mathrm{m}^{2}\right)$. Fifty patients were treated with two cycles of docetaxel $\left(60 \mathrm{mg} / \mathrm{m}^{2}\right)$ and cisplatin $\left(80 \mathrm{mg} / \mathrm{m}^{2}\right)$ delivered on days 1 and 22 of radiotherapy [6]. Twenty-two patients received at least four cycles of docetaxel $\left(30 \mathrm{mg} / \mathrm{m}^{2}\right)$ and cisplatin $\left(35 \mathrm{mg} / \mathrm{m}^{2}\right)$ per week. Another 44 were treated with two cycles of $60 \mathrm{mg} / \mathrm{m}^{2}$ of cisplatin administered on days 1 and 29 and $300 \mathrm{mg} / \mathrm{m}^{2} / 24 \mathrm{~h}$ of 5 -FU administered on days $1-3$ and days 29-31 [7]. The remaining 23 patients received other regimens of chemotherapy such as navelbine plus cisplatin.

\section{Toxicity and response assessment}

The evaluation of acute treatment toxicities consisted of history and physical examination, documentation of performance status, complete blood count, and toxicities scoring. A routine barium swallow was performed by the radiation oncologist at doses of 20,40 and 60 Gy. One day before starting the next chemotherapy cycle, a full blood count and serum chemistry was carried out. The acute toxicity of radiotherapy and chemotherapy were evaluated according to CTC version 2.0. The treatment effect was assessed at one month after finishing treatment, and included physical examination and history, endoscopy, and barium swallow. Treatment response was according to the guidelines for solid tumors [8] as follows: a complete response $(\mathrm{CR})$ was defined as the complete disappearance of clinically detectable tumor masses; a partial response (PR) required a $>30 \%$ decrease in the sum longest diameter of tumor for at least 1 month; the appearance of new lesions or a $20 \%$ increase in the sum longest diameter of an existing tumor was reported as progressive disease (PD). Neither PR nor PD criteria met the standards for stable disease (SD).

\section{Follow-up and statistical analysis}

Overall survival and progression-free survival were calculated for each potential prognostic factor with the Kaplan-Meier method and were measured from the first day of diagnosis or censored at the date of the last followup. The log-rank test was used for testing significance, and the level of statistical significance was set at $p<0.05$. Multivariate analyses were performed by Cox regression. The last follow-up evaluation was performed in April 2013. All statistical analyses were performed using SPSS 16.0 software (SPSS Inc., Chicago, IL, USA).

\section{Results}

\section{Patient characteristics}

Between 2002 and 2011, 139 consecutive patients with inoperable esophageal squamous cell carcinoma were studied. The demographic data of the patients are shown in Table 1. There were 115 (82.7\%) male and 24 (17.3\%) female patients with a median age of 63 years (range: 34-86). The median follow-up was 23 months (range: 2-117 months). 
Table 1 Patient characteristics

\begin{tabular}{|c|c|c|}
\hline Characteristics & No. & $\%$ \\
\hline \multicolumn{3}{|l|}{ Sex } \\
\hline Male & 115 & 82.7 \\
\hline Female & 24 & 17.3 \\
\hline \multicolumn{3}{|l|}{ Histological grading } \\
\hline G1 & 12 & 8.6 \\
\hline G2 & 61 & 43.9 \\
\hline G3/4 & 38 & 27.3 \\
\hline Gx & 28 & 20.1 \\
\hline \multicolumn{3}{|l|}{ Tumor site } \\
\hline Proximal & 54 & 38.8 \\
\hline Medial & 75 & 54.0 \\
\hline Distal & 10 & 7.2 \\
\hline \multicolumn{3}{|l|}{ Tumor legngth } \\
\hline$\leq 5 \mathrm{~cm}$ & 65 & 46.8 \\
\hline$>5 \mathrm{~cm}$ & 74 & 53.2 \\
\hline \multicolumn{3}{|l|}{ T stage } \\
\hline $\mathrm{T} 1 / 2$ & 17 & 12.2 \\
\hline T3 & 68 & 48.9 \\
\hline T4 & 54 & 38.8 \\
\hline \multicolumn{3}{|l|}{ M stage } \\
\hline M1a & 54 & 38.8 \\
\hline $\mathrm{M} 1 \mathrm{~b}$ & 85 & 61.2 \\
\hline \multicolumn{3}{|l|}{ Laterality } \\
\hline Unilateral CLNM & 106 & 76.2 \\
\hline Bilateral CLNM & 33 & 23.7 \\
\hline \multicolumn{3}{|l|}{ RT dose } \\
\hline$<60$ Gy & 45 & 32.4 \\
\hline$\geq 60 G y$ & 94 & 67.6 \\
\hline \multicolumn{3}{|l|}{ Chemotherapy mode } \\
\hline Induced $C T+R C T$ & 29 & 20.9 \\
\hline $\mathrm{RCT}$ & 110 & 79.1 \\
\hline \multicolumn{3}{|l|}{ Concurrent chemotherapy } \\
\hline Cisplatin+5-Fu & 44 & 31.7 \\
\hline Cisplatin+ docetaxel & 72 & 51.8 \\
\hline Other & 23 & 16.5 \\
\hline \multicolumn{3}{|l|}{ Response to treatment } \\
\hline$C R$ & 48 & 34.5 \\
\hline Non-CR & 91 & 65.5 \\
\hline
\end{tabular}

RT: radiotherapy; CT: chemotherapy; RCT: radiochemotherapy; CLNM: cervical lymph nodal metastases.

\section{Response to treatment and survival}

Of the 139 eligible patients, 48 (34.5\%) achieved a CR; and 71 (51.1\%) patients demonstrated a PR according to the guidelines for solid tumors, which resulted in a response rate of $76.3 \%$. Nine $(6.5 \%)$ patients achieved SD and the remaining 11 patients achieved PD (7.9\%).

The 1- 2- and 3-year survival rates were $68.2 \%, 39.1 \%$, and $27.9 \%$, respectively; and the 1,2 , and 3 years of progression-free survival rates were $51.9 \%, 29.8 \%$, and $20.1 \%$, respectively (Figure 1 ).

\section{Treatment-related toxicity}

Most treatment-related and documented acute toxicities were grades 1 and 2 . The most common grades 3 and 4 toxicities were leukopenia (48 patients; $34.5 \%$ ) and gastrointestinal toxicity (15 patients; $10.8 \%$ ). Laryngeal edema occurred in one patient. No therapy-related deaths occurred. Acute treatment-related toxicities were evaluated based on the CTC 3.0 and are listed in Table 2.

Fifteen patients (10.8\%) developed an esophagostenosis in subsequent follow-up. Radiotherapy-related lung disease was diagnosed in seven patients (5.0\%). One patient developed paralysis of the vocal cord.

\section{Association of survival and clinicopathologic factors}

Univariate analyses were performed for each prognostic factor. Response to treatment $(p<0.001)$, pathological grade $(p=0.047)$, T stage $(p=0.001)$, laterality of cervical lymph nodal metastases $(p=0.009)$, and chemotherapy regimen $(p=0.003)$ had an effect on overall survival rate (Table 2). Gender, primary tumor length, radiotherapy dose, M stage and introduction chemotherapy had no statistically significant impact on overall survival; it is worth noting that tumor location approached statistical significance $(p=0.055)$.

In the univariate analyses of the PFS, response to treatment $(p<0.001)$, pathological grade $(p=0.038)$, T stage ( $p=0.002)$, laterality of cervical lymph nodal metastases ( $p=0.006)$, and chemotherapy regimen $(p=0.034)$ had an effect on progression-free survival rate. Sex, primary tumor length, radiotherapy dose, $\mathrm{M}$ stage, tumor location, and introduction chemotherapy had no statistically significant impact on progression-free survival.

The 3-year OS of the patients with grade IVa disease (primary lesions located in the upper-third esophagus) was $35.9 \%$, which was better than that of the patients with grade IVb disease (primary lesions located in the middleand lower-third of the esophagus), for which the 3-year OS was $23.0 \%$. However, this difference was not statistically significant ( $p=0.086$; Figure 2 ).

Patients who received induced chemotherapy did not show a benefit in OS ( $p=0.106$; Figure $3 \mathrm{~A})$ and PFS ( $p=0.253$ ) compared with patients who received chemoradiotherapy.

After treatment, patients with a CR had an obviously better prognosis than non-CR patients. The 3-year OS of patients with a CR was 53.7\%; whereas the 3 -year OS of non-CR patients was only $20.1 \%(p<0.001)$. The 3 -year 

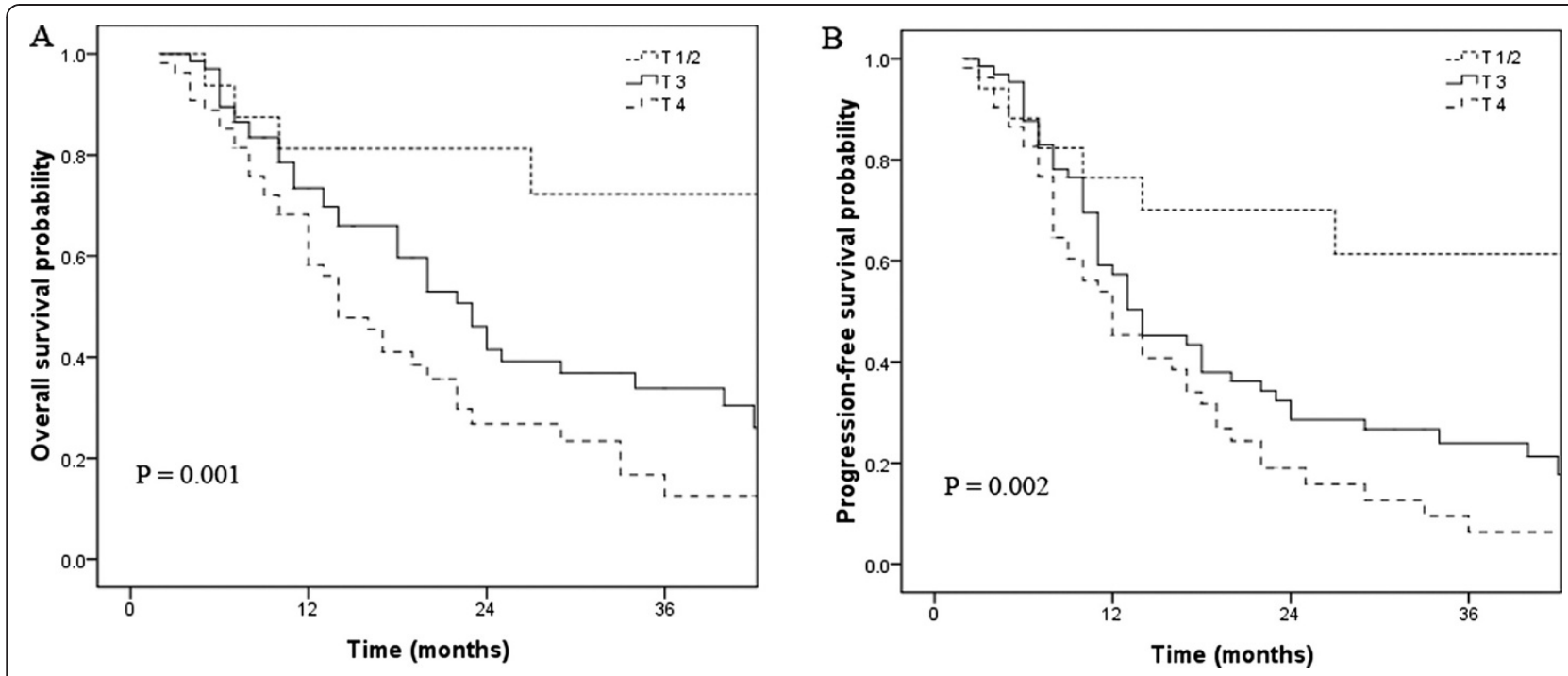

Figure 1 Overall survival (A) and progression-free survival (B) according to clinical T stage.

PFS of CR and non-CR patients was $11.4 \%$ and $38.6 \%$, respectively $(p<0.001)$.

Patients with T1/2 disease had a better 3-year OS than stage T3 and T4 tumors $(36.1 \%$ vs. $30.4 \%$ vs. $12.5 \%$ $p=0.001)$. The 3 -year PFS of patients with T1/T2 disease was significantly better than that of patients with T3 and T4 disease (30.7\% vs. $21.3 \%$ vs. $6.3 \%$; $p=0.002)$.

Patients with unilateral cervical lymph nodal metastases had a better 3-year OS (33.5\%) and a better PFS (26.4\%) compared with those with bilateral metastases (3-year OS rate, $14.8 \%, p=0.009$; 3 -year PFS rate, $4.3 \%, p=0.006$ ).

The 3-year OS and PFS of patients who received cisplatin and docetaxel were $37 \%$ and $22.7 \%$, respectively. The 3-year OS and PFS of patients who received cisplatin and 5 -FU were $14.5 \%$ and $13.1 \%$, respectively ( $p=0.003$ ), while the 3-year OS and PFS rates of patients who received other regimens were $13.3 \%$ and $11.0 \%$, respectively $(p=0.034)$.

\section{Multivariate analysis}

Multivariate analysis was performed for OS, including factors found to be significant on univariate analysis. Additionally, a backward stepwise Cox regression analysis was performed. According to the analysis, response to

Table 2 Acute toxicity according to CTC v 3.0

\begin{tabular}{llllll}
\hline Toxicity & Grade 0 & Grade 1 & Grade 2 & Grade 3 & Grade 4 \\
& $\mathbf{n ~ ( \% )}$ & $\mathbf{n ~ ( \% )}$ & $\mathbf{n ~ ( \% )}$ & $\mathbf{n ~ ( \% )}$ & $\mathbf{n ~ ( \% ) ~}$ \\
\hline Anemia & $27(19.4)$ & $53(38.1)$ & $52(37.4)$ & $7(5.0)$ & $0(0)$ \\
Leukocytopenia & $17(12.2)$ & $44(31.7)$ & $60(43.1)$ & $30(21.6)$ & $18(12.9)$ \\
Thrombopenia & $50(40.0)$ & $45(32.4)$ & $24(17.3)$ & $18(12.9)$ & $2(1.4)$ \\
Gastrointestinal & $17(12.2)$ & $75(54.0)$ & $32(23.0)$ & $14(10.1)$ & $1(0.7)$ \\
\hline
\end{tabular}

treatment $(p<0.001)$, clinical T stage $(p=0.007)$, pathological grade $(p=0.002)$, and laterality of cervical lymph nodal metastases $(p=0.023)$ were independent prognostic factors for OS. Concurrent chemotherapy $(p=0.117)$ was not statistically significant.

\section{Discussion}

Cervical lymph nodal metastases (CLNM) are not rare in thoracic esophageal squamous carcinoma. Huang et al. reported the pattern of thoracic SCC lymph nodal metastases after esophagectomy. In their study, the rates of CLNM in patients with upper, middle and lower thoracic tumors were $16.7 \%$ (9/54), 4.0\% (27/680) and 1.0\% $(5 / 343)$, respectively [9]. It is worth pointing out that their cases all received surgery and there is an inevitable operation selection bias. The CLNM rates may be higher for patients with inoperable SCC treated with chemoradiotherapy in consideration of more advanced staging.

Previous literature reporting the prognosis of thoracic esophageal squamous carcinoma with CLNM (stage IV) is conflicting $[2,10]$. Shimada et al. retrospectively analyzed 88 patients who were diagnosed with thoracic esophageal cancer with CLNM and reported that the 5-year OS rate of these patients was 26\% [2]. The Japanese Society for Esophageal Diseases has divided cervical nodes into four groups: cervical paraesophageal nodes, deep cervical nodes, retropharyngeal nodes, and supraclavicular nodes, and involvement of the cervical paraesophageal nodes was defined as stage N1 in the case of cancers of the upper third of the esophagus [11]. According to the Chinese nonoperative stage of esophageal cancer, patients with CLNM are considered to be stage N1 (cervical esophageal cancer) or N2 (thoracic esophageal cancer) [12]. Although patients with CLNM only were graded as stage IV according to the 

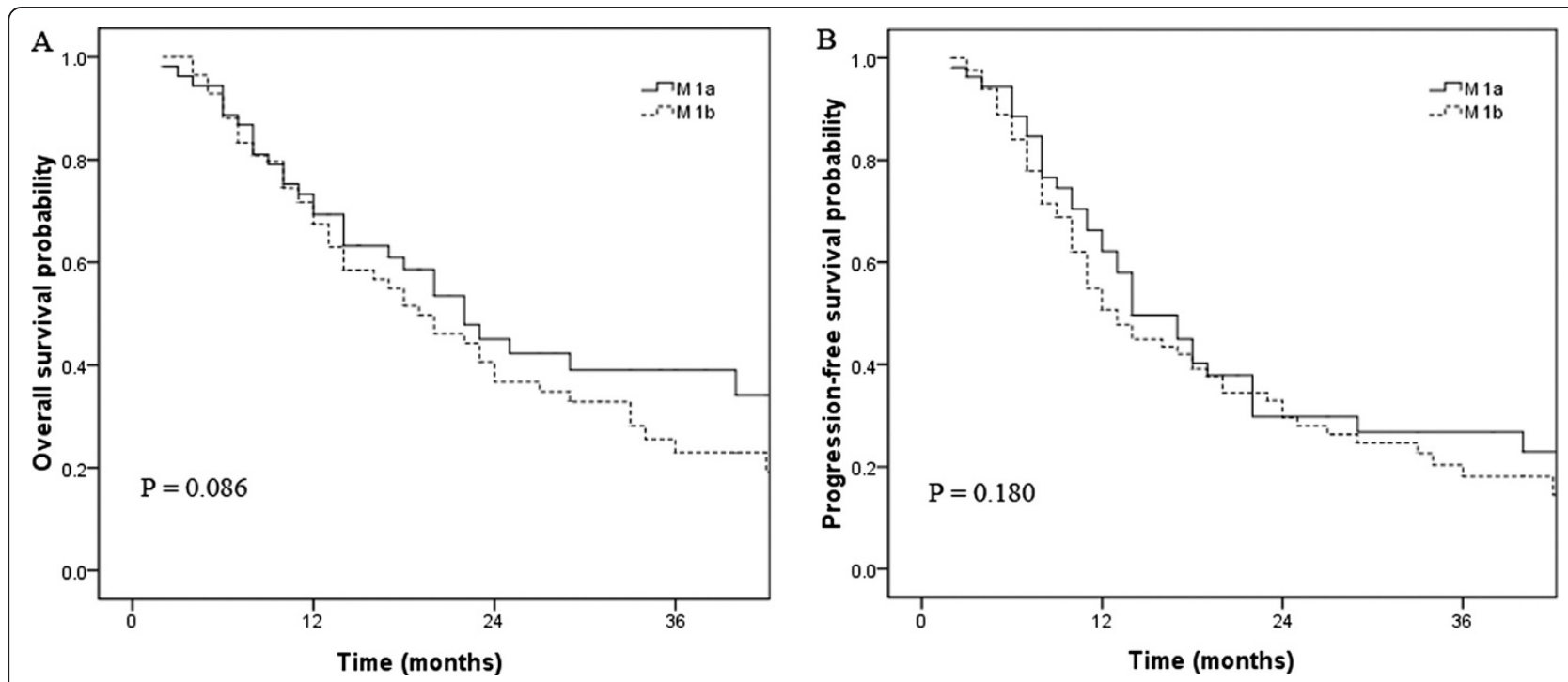

Figure 2 Overall survival (A) and progression-free survival (B) according to $M$ stage.

AJCC 6th TNM system, we still adopted the more radical treatment to expect a better prognosis.

We performed a comprehensive assessment of the efficacy and prognostic factors of chemoradiotherapy for thoracic esophageal squamous carcinoma with CLNM only, and have shown that the prognosis of these patients is not dismal, despite it being stage IV. In our study, the 3-year OS and PFS rates of these patients were $27.9 \%$ and $20.1 \%$, respectively. The multivariate analysis showed that response to treatment $(p<0.001)$, clinical T stage $(p=0.007)$, pathological grade $(p=0.002)$, and laterality of cervical lymph nodal metastases $(p=0.023)$ have a significant bearing on overall survival. The main pattern of treatment failure is still the local recurrence $(61 / 139,43.9 \%)$.

Locoregional control remains the major problem in patients with SCC treated with chemoradiotherapy. In our study, patients who achieved a complete response (CR) had an obviously better survival than those who did not (non-CR), which is consistent with previous literature [13,14]. Ohtsu et al. reported that a CR rate of $33 \%$ and a 3 -year survival rate of $23 \%$ were achieved in patients with unresectable T4 tumors and/or M1 LYM (lymphatic metastasis) disease. In this study, the chemoradiotherapy consisted of a total radiation dose of $60 \mathrm{~Gy}$
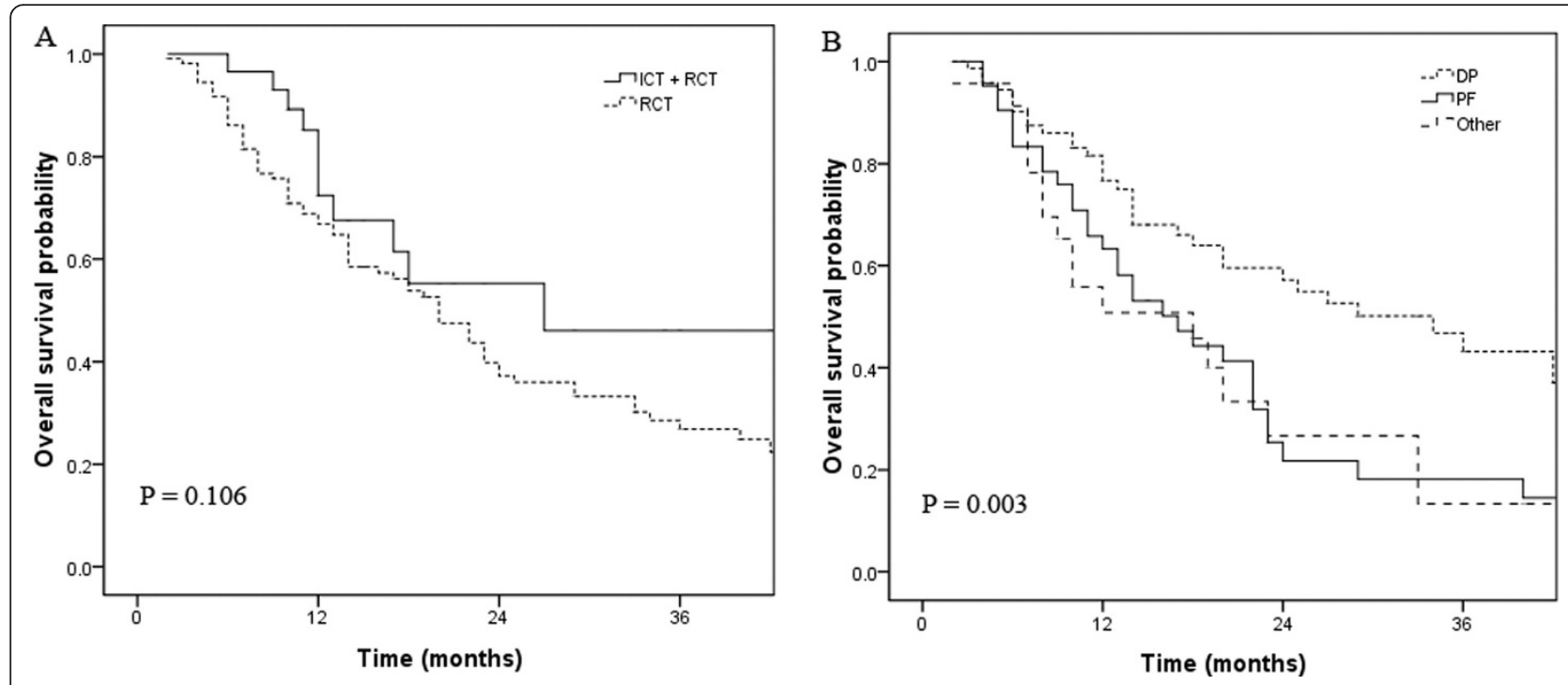

Figure 3 Overall survival according to chemotherapy mode (A) and concurrent CRT regimen (B). 
with concurrent fluorouracil $\left(400 \mathrm{mg} / \mathrm{m}^{2}\right)$ and cisplatin $\left(40 \mathrm{mg} / \mathrm{m}^{2}\right)$, followed by two courses of fluorouracil $\left(800 \mathrm{mg} / \mathrm{m}^{2} / 24\right.$ hours for 5 days) and cisplatin $(80 \mathrm{mg} /$ $\mathrm{m}^{2}$ on day 1) [14].

The primary lesion $\mathrm{T}$ stage also has a bearing on the prognosis. In our study, the survival of patients with T1/2 disease is better than that of those with a T3 lesion, and the prognosis of patients with $\mathrm{T} 3$ disease is better than that of those with $\mathrm{T} 4$ lesions. Increasing depth of tumor invasion is associated with the presence of lymphatic dissemination and thus leads to the unfavorable prognosis [15]. The same results were achieved in the analysis of the PFS. In accordance with our results, Kaneko et al. reported that the prognosis of patients with T3 lesions was better than that of those with T4 tumors with squamous cell carcinoma of the esophagus and concluded that the efficacy and survival of patients treated with chemoradiotherapy are related to the T stage [16].

It is worth pointing out that the laterality of the CLNM has a bearing on the prognosis of patients with thoracic esophageal squamous carcinoma and CLNM ( $p=0.023)$. The results may be attributed to the fact that patients with unilateral CLNM have an earlier staging than patients with bilateral CLNM. Skip metastasis may be another factor that influences prognosis. Prenzel et al. reported that skip metastases are associated with better 5-year survival rates and have a higher rate in cancer of the middle and upper thirds of the esophagus [17].

The 7th edition AJCC staging system shows that the tumor location is a component of staging and that the prognosis of the lower third of esophageal cancer is better than that of the upper and middle thirds of the esophagus [18]. In this regard, our data did not reveal a significant impact for tumor location. However, there were trends observed ( $p=0.055)$. This result may be owing to the relatively small number of patients. On the other hand, the patients with stage IVa disease (primary lesions located in the upper third of the esophagus) had a better (but not significant) prognosis than patients with stage IVb disease (primary lesions located in the middle and lower thirds of the esophagus), which is in accordance with the 6th AJCC staging system.

The RTOG 85-01 clinical trial demonstrated that combined chemoradiotherapy has a significant advantage over radiotherapy only, in patients with esophageal cancer. But, the concurrent chemotherapy regimen is far from conclusive [19]. In a phase I trial, Day et al. reported that docetaxel, cisplatin and concurrent radical radiotherapy is safe and efficient for locally advanced esophageal cancer with a complete response of $33 \%$. The progression-free survival at 2 years was $49.7 \%$ and at 5 years was $26.5 \%$ [20]. In addition, a phase III trial reported that the pathological complete response (pCR) of preoperative chemoradiotherapy for esophageal carcinoma was $29 \%$ and the pCR of esophageal squamous-cell carcinoma was $49 \%$. These findings reveal that the concurrent carboplatin plus paclitaxel regimen is rather effective compared with the previous regimen [21]. In a multicenter phase II trial, a pCR rate of $38 \%$ was achieved in patients with esophageal squamous cell cancer, while the pCR of patients with adenocarcinoma was only $16 \%$ [22]. In the univariate analyses of our study, the chemotherapy regimen had a significant influence on the OS and PFS ( $p=0.003$ and 0.034 , respectively). But, the chemotherapy regimen did not reach significance in the multivariate analysis $(p=0.117)$. We deduced that this result is chiefly because of the small number of patients included in our study.

We did not observe a survival benefit for higher radiation dose when compared with lower radiation dose, which is in accordance with the results of the INT0123 study. The INT0123 trial reported that a higher radiation dose did not increase survival or local/regional control in patients with M0 esophageal cancer (by increasing the radiation dose from 50.4 Gy to $64.8 \mathrm{~Gy}$ ) with a concurrent chemotherapy regimen of cisplatin/5-FU [23]. In a phase I/ II trial, Wu et al. reported the treatment effect of patients with esophageal squamous cell carcinoma who received three-dimensional conformal radiation therapy. The 2-year local disease progression-free rate and distant metastasisfree rate were $36 \%$ and $56 \%$, respectively, which were disappointing [24]. Our results also showed that a higher radiation dose ( $>60$ Gy) did not increase the overall survival or progression-free survival in the M1 patients ( $p=0.107$ and 0.605 , respectively).

Although numerous studies have indicated that tumor length influences the prognosis of esophageal cancer $[3,25]$, the patients in these studies had an earlier stage of disease. Yendamuri et al. reported that esophageal tumor length is independently associated with long-term survival, but found no statistical significance in the stage III patients [3]. The authors concluded that tumor length may be a better predictor of locoregional rather than distant control of disease. In our study, we only included the patients with stage IV disease. Our findings also reveal that primary tumor length does not have a significant impact in the prognostic analysis $(p=0.911)$, which we attribute to more advanced stages and bulky lesions in our cohort.

The current study is limited by its retrospective design. Although the cases of cervical lymph nodal metastases in our study were based on radiology, the specificity of CT in detecting nodal metastases is $96.7 \%$, and the accuracy is $76.6 \%$ for squamous cell carcinoma of the esophagus; here, nodal enlargement greater than $10 \mathrm{~mm}$ was considered indicative of involvement [26]. Considering these aspects of our study, longer follow-up and larger studies are needed in the future. 


\section{Conclusion}

The prognosis of esophageal cancer with CLNM only is not completely bleak. Concurrent chemoradiotherapy is an important and hopeful treatment option for these patients. The response to treatment, $\mathrm{T}$ stage, pathological grade and laterality of cervical lymph nodal metastases are significant prognostic factors for long-term survival.

\section{Competing interests}

The authors declare that they have no competing interests.

\section{Authors' contributions}

Conceived and designed the experiments: MZL; PZ; MX. Performed the experiments: LZ. Analyzed the data: QQL; SLL. Contributed reagents/ materials/analysis tools: LRH; JXS. Wrote the manuscript: PZ; MX. Other (please specify): none. All authors read and approved the final manuscript.

\section{Acknowledgements}

This work was supported by the grant from the Sci-Tech Project Foundation of Guangdong Province (No. 2012B031800287).

\author{
Author details \\ ${ }^{1}$ State Key Laboratory of Oncology in South China, Collaborative Innovation \\ Center for Cancer Medicine, Cancer Center, Sun Yat-sen University, \\ Guangzhou 510060, People's Republic of China. ${ }^{2}$ Department of Radiation \\ Oncology, Cancer Center, Sun Yat-sen University, Guangzhou 510060, \\ People's Republic of China. ${ }^{3}$ Imaging Diagnosis and Interventional Center, \\ Cancer Center, Sun Yat-sen University, Guangzhou 510060, People's Republic \\ of China.
}

Received: 12 November 2013 Accepted: 6 November 2014 Published online: 26 November 2014

\section{References}

1. Siegel R, Naishadham D, Jemal A: Cancer Statistics, 2013. CA Cancer J Clin 2013, 63:11-30

2. Shimada H, Shiratori T, Okazumi S, Matsubara H, Nabeya Y, Shuto K, Shimizu T, Hayashi H, Ochiai T: Surgical outcome of patients with thoracic esophageal cancer positive for cervical lymph nodes. Hepatogastroenterology 2007, 54:100-103.

3. Yendamuri S, Swisher SG, Correa AM, Hofstetter W, Ajani JA, Francis A, Maru D, Mehran RJ, Rice DC, Roth JA, Walsh GL, Vaporciyan AA: Esophageal tumor length is independently associated with long-term survival. Cancer 2009, 115:508-516.

4. Lagarde SM, ten Kate FJ, Reitsma JB, Busch OR, van Lanschot JJ: Prognostic factors in adenocarcinoma of the esophagus or gastroesophageal junction. J Clin Oncol 2006, 24:4347-4355.

5. Semrau R, Herzog SL, Vallböhmer D, Kocher M, Hölscher AH, Müller RP: Prognostic factors in definitive radiochemotherapy of advanced inoperable esophageal cancer. Dis Esophagus 2012, 25:545-554.

6. Li QQ, Liu MZ, Hu YH, Liu H, He ZY, Lin HX: Definitive concomitant chemoradiotherapy with docetaxel and cisplatin in squamous esopheageal carcinoma. Dis Esophagus 2010, 23:253-259.

7. Liu H, Lu L, Zhu Q, Hao Y, Mo Y, Liu M, Hu Y, Cui N, Rong T: Cervical nodal metastases of unresectable thoracic esophageal squamous cell carcinoma Characteristics of long-term survivors after concurrent chemoradiotherapy. Radiother Oncol 2011, 99:181-186.

8. Therasse P, Arbuck SG, Eisenhauer EA, Wanders J, Kaplan RS, Rubinstein L, Verweij J, Van Glabbeke M, van Oosterom AT, Christian MC, Gwyther SG: New guidelines to evaluate the response to treatment in solid tumors. European Organization for Research and Treatment of Cancer, National Cancer Institute of the United States, National Cancer Institute of Canada. J Natl Cancer Inst 2000, 92:205-216.

9. Huang W, Li B, Gong H, Yu J, Sun H, Zhou T, Zhang Z, Liu X: Pattern of lymph node metastases and its implication in radiotherapeutic clinical target volume in patients with thoracic esophageal squamous cell carcinoma: A report of 1077 cases. Radiother Oncol 2010, 95:229-233.
10. Tong DK, Kwong DL, Law S, Wong KH, Wong J: Cervical nodal metastasis from intrathoracic esophageal squamous cell carcinoma is not necessarily an incurable disease. J Gastrointest Surg 2008, 12:1638-1645.

11. Isono K, Uchida Y, Watanabe H: Guidelines for clinical and pathologic studies on carcinoma of the esophagus, ninth edition. Esophagus 2004, 1:61-88.

12. Chinese expert group of nonoperative esophageal cancer staging: Standard clinical staging of nonoperative therapy of esophageal cancer (Draft). Chin J Radiat Oncol 2010, 19:179-180.

13. Chen EC, Liu MZ, Hu YH, Li QQ, Liu H, Cai L, Liu H, Lin HX, Huang Y, Wang HY, Cui NJ: Multivariate prognostic analysis for patients with unresectable esophageal carcinoma after concurrent chemoradiotherapy. Chin J Cancer 2005, 24:731-734.

14. Ohtsu A, Boku N, Muro K, Chin K, Muto M, Yoshida S, Satake M, Ishikura S, Ogino T, Miyata Y, Seki S, Kaneko K, Nakamura A: Definitive chemoradiotherapy for T4 and/or M1 lymph node squamous cell carcinoma of the esophagus. J Clin Oncol 1999, 17:2915-2921.

15. Rice TW, Zuccaro G Jr, Adelstein DJ, Rybicki LA, Blackstone EH, Goldblum JR: Esophageal carcinoma: depth of tumor invasion is predictive of regional lymph node status. Ann Thorac Surg 1998, 65:787-792.

16. Kaneko K, Ito H, Konishi K, Kurahashi T, Ito T, Katagiri A, Yamamoto T, Kitahara T, Mizutani Y, Ohtsu A, Mitamura K: Definitive chemoradiotherapy for patients with malignant stricture due to T3 or T4 squamous cell carcinoma of the oesophagus. Br J Cancer 2003, 88:18-24.

17. Prenzel KL, Bollschweiler E, Schröder W, Mönig SP, Drebber U: Prognostic relevance of skip metastases in esophageal cancer. Ann Thorac Surg 2010, 90:1662-1667.

18. Edge SB, Byrd DR, Compton CC: American Joint Committee on Cancer (AJCC) Cancer Staging Manual. 7th edition. Chicago: Springer Inc.; 2010.

19. Herskovic A, Martz K, Al-Sarraf M, Leichman L, Brindle J, Vaitkevicius V, Cooper J, Byhardt R, Davis L, Emami B: Combined chemotherapy and radiotherapy compared with radiotherapy alone in patients with cancer of the esophagus. N Engl J Med 1992, 326:1593-1598.

20. Day FL, Leong T, Ngan S, Thomas R, Jefford M, Zalcberg JR, Rischin D, McKendick J, Milner AD, Di lulio J, Matera A, Michael M: Phase I trial of docetaxel, cisplatin and concurrent radical radiotherapy in locally advanced oesophageal cancer. Br J Cancer 2011, 104:265-271.

21. van Hagen $P$, Hulshof MC, van Lanschot JJ, Steyerberg EW, van Berge Henegouwen MI, Wijnhoven BP, Richel DJ, Nieuwenhuijzen GA, Hospers GA, Bonenkamp JJ, Cuesta MA, Blaisse RJ, Busch OR, ten Kate FJ, Creemers GJ, Punt CJ, Plukker JT, Verheul HM, Spillenaar Bilgen EJ, van Dekken H, van der Sangen MJ, Rozema T, Biermann K, Beukema JC, Piet AH, van Rij CM, Reinders JG, Tilanus HW, van der Gaast A, CROSS Group: Preoperative chemoradiotherapy for esophageal or junctional cancer. N Engl J Med 2012, 366:2074-2084.

22. Ruhstaller T, Widmer L, Schuller JC, Roth A, Hess V, Mingrone W, von Moos R, Borner M, Pestalozzi BC, Balmermajno S, Köberle D, Terraciano L, Schnider A, Bodis S, Popescu R, Swiss Group for Clinical Cancer Research (SAKK): Multicenter phase II trial of preoperative induction chemotherapy followed by chemoradiation with docetaxel and cisplatin for locally advanced esophageal carcinoma (SAKK 75/02). Ann Oncol 2009, 20:1522-1528.

23. Minsky BD, Pajak TF, Ginsberg RJ, Pisansky TM, Martenson J, Komaki R, Okawara G, Rosenthal SA, Kelsen DP: INT 0123 (Radiation Therapy Oncology Group 94-05) Phase III trial of combined-modality therapy for esophageal cancer: high-dose versus standard-dose radiationtherapy. J Clin Oncol 2002, 20:1167-1174.

24. Wu KL, Chen GY, Xu ZY, Fu XL, Qian H, Jiang GL: Three-dimensional conformal radiation therapy for squamous cell carcinoma of the esophagus: A prospective phase I/II study. Radiother Oncol 2009, 93:454-457.

25. Bollschweiler E, Baldus SE, Schröder W, Schneider PM, Hölscher AH: Staging of esophageal carcinoma: length of tumor and number of involved regional lymph nodes. Are these independent prognostic factors? J Surg Oncol 2006, 94:355-363.

26. Kim K, Park SJ, Kim BT, Lee KS, Shim YM: Evaluation of lymph node metastases in squamous cell carcinoma of the esophagus with positron emission tomography. Ann Thorac Surg 2001, 71:290-294.

\section{doi:10.1186/s13014-014-0256-9}

Cite this article as: Zhang et al:: Efficacy and prognostic analysis of chemoradiotherapy in patients with thoracic esophageal squamous carcinoma with cervical lymph nodal metastasis alone. Radiation Oncology 2014 9:256. 